Jurnal Pemberdayaan: Publikasi Hasil Pengabdian kepada Masyarakat

Vol. 2, No. 2,Agustus 2018, Hal. 257-264

ISSN: 2088 4559; e-ISSN: XXXX-XXXX

DOI:

\title{
PENANGGULANGAN HIPERTENSI DI DUSUN KRETEK RT 09 BANGUNTAPAN BANTUL
}

\author{
Surahma Asti Mulasari ${ }^{1}$ \\ Fakultas Kesehatan Masyarakat Universitas Ahmad Dahlan Yogyakarta \\ Email : surahma.mulasari@ikm.uad.ac.id
}

\begin{abstract}
ABSTRAK
Hipertensi merupakan masalah kesehatan masyarakat di dunia baik negara maju maupun negara berkembang. Permasalahan kesehatan yang perlu diperhatikan di Dusun Kretek salah satunya adalah hipertensi. Tujuan kegiatan pengabdian ini adalah untuk meningkatkan pengetahuan, sikap dan perilaku masyarakat terkait penyakit hipertensi dengan harapan dapat mencegah meningkatnya penyakit hipertensi di Dusun Kretek, Banguntapan, Bantul. Metode yang diterapkan dalam program kegiatan pengabdian ini adalah dengan metode ceramah dengan media promosi kesehatan berupa leaflet tentang penyakit hypertensi. Berdasarkan pada hasil masih banyak warga yang terdiagnosis hipertensi namun tidak melakukan pengobatan atau masih banyak warga yang belum mengetahui apakah dirinya terdiagnosis hipertensi atau tidak. Hal tersebut menjadi dasar kegiatan pengabdian untuk meningkatkan pengetahuan sikap dan perilaku untuk menurunkan resiko hipertensi di lokasi pengabdian.
\end{abstract}

Kata Kunci: Hipertensi, Pencegahan, Pendidikan Kesehatan

\begin{abstract}
Hypertension is a public health problem in the world, both developed and developing countries. Health problems that need to be considered in Dusun Kretek are hypertension. The purpose of this service activity was to increase the knowledge, attitudes and behavior of people related to hypertension in the hope of preventing the increase of hypertension in Dusun Kretek, Banguntapan, Bantul. The method applied in this program of service activities is the lecture method with health promotion media in the form of leaflets about hypertension. Based on the results of data collection on residents in Kretek Hamlet RT 09, there are still many people diagnosed with hypertension but do not take medication or there are still many people who do not know whether they are diagnosed with hypertension or not. This was the basis of the service activities to improve knowledge of attitudes and behaviors to reduce the risk of hypertension at the service location
\end{abstract}

Keywords: Hypertension, Health Education, Prevention

\section{PENDAHULUAN}

Dusun Kretek terletak di Desa Jambidan, Kecamatan Banguntapan, Kabupaten Bantul, Provinsi Daerah Istimewa Yogyakarta yang termasuk dalam zona perbatasan wilayah dataran rendah dengan wilayah Dataran Tinggi Kecamatan Piyungan dimana 
lokasi tersebut sudah termasuk di daerah batuan kapur. Dusun Kretek terdiri dari 4 Kampung dengan 9 RT. Jumlah penduduk Dusun Kretek tahun 2017 tercatat sebanyak 1630 jiwa. Penduduk laki-laki berjumlah 845 jiwa, perempuan 785 jiwa.

Dusun Kretek memiliki tanah yang sangat subur karena dekat dengan sungai opak yang selalu mengalir, sehingga masyarakat di Dusun Kretek tidak mengalami kekurangan air pada musim kering. Tanaman pertanian pada umumnya adalah padi, dan perkebunan, cenderung banyak warga menanam buah pisang, tebu dan kacang. Organisasi kemasyarakatan di Dusun Kretek cukup baik. Hal ini bisa dilihat dari banyaknya organisasi yang terbentuk seperti PKK, POSYANDU, Karang Taruna, LPMD dan Takmir masjid, Perkumpulan Pemuda, dan lainnya. Masyarakat Dusun Kretek mayoritas menganut Agama Islam dan beberapa menganut agama lain. Masyarakat Dusun Kretek pada umumnya memiliki tingkat kehidupan yang sudah baik. Pada umumnya masyarakat Dusun Kretek bermata pencaharian sebagai buruh pembuat batu bata, namun terdapat juga beberapa warga yang bermata pencaharian lain seperti PNS dan lainnya (Dinkes, 2016).

Kami menentukan prioritas masalah masyarakat Dusun Kretek dengan metode USGF. Metode USGF merupakan salah satu metode menentukan prioritas masalah dari 4 aspek yaitu Urgeny, Seriousness, Growth dan Facilitate. Untuk mempermudah perbandingan diperlukan penilaian sebagai pembanding dan memasukkan semua nilai tersebut di matrik USGF dengan menjumlahkan keempat aspek tersebut. Berdasarkan hasil penentuan prioritas masalah dan dilihat dari beberapa aspek USGF didapatkan hasil bahwa prioritas masalah yang utama adalah hipertensi. Maka kami mengambil prioritas permasalahan terkait penyakit hipertensi sebagai prioritas masalah yang akan kami bahas lebih dalam.

Nuraeni dkk. (2017) dalam penelitiannya mengatakan bahwa sebagai salah satu solusi untuk menekan kejadian hipertensi ini dapat dilakukan dengan pendidikan kesehatan kepada masyarakat. Hipertensi dapat dikontrol dengan berbagai upaya menjaga gaya hidup. Hal ini dapat tercapai jika pengetahuan masyarakat mengenai pencegahan dan perawatan hipertensi baik. Saat ini kementerian kesehatan berupaya meningkatkan promosi kesehatan melalui komunikasi, informasi dan edukasi. Upaya ini diharapkan dapat meningkatkan pengetahuan, kesadaran dan keinginan masyarakat dalam mencegah dan melakukan perawatan di rumah, sehingga angka hipertensi dapat terkontrol ataupun dicegah pada masyarakat yang berisiko. 


\section{METODE}

Metode yang diterapkan dalam program kegiatan pengabdian masyarakat ini adalah dengan metode ceramah dan tanya jawab. Materi yang disajikan berkaitan dengan penyakit hipertensi, yaitu meliputi definisi, ciri-ciri, penyebab, cara pencegahan dan pengobatan penyakit. Peserta juga diberi leaflet mengenai penyakit hipertensi dengan tujuan agar peserta penyuluhan dapat lebih meningkatkan kemampuan dalam menyerap materi yang disampaikan oleh narasumber, selain itu peserta dapat membaca kembali materi penyuluhan di rumah, apabila peserta ada yang lupa mengenai materi penyuluhan yang sudah disampaikan sebelumnya. Kegiatan pengabdian dilakukan bersama dengan mahasiswa FKM UAD yang berjumlah 29 mahasiswa. Kegiatan dilaksanakan pada bulan Juli 2018 dan membutuhkan waktu dua hari. Sasaran kegiatan ini adalah semua keluarga yang ada di Dusun Kretek, Kecamatan Banguntapan, Kabupaten Bantul, Yogyakarta yaitu sebanyak 63 KK. Masyarakat yang hadir dalam kegiatan ini sebanyak 22 orang/KK dari jumlah undangan 63 orang.

\section{HASIL, PEMBAHASAN DAN DAMPAK}

Berdasarkan pada hasil pendataan pada warga di Dusun Kretek dapat diketahui bahwa jumlah kepala keluarga (KK) yang menderita hipertensi dan melakukan pengobatan secara teratur hanya ada $3 \mathrm{KK}$. Sedangkan untuk keluarga yang terdiagnosis hipertensi dan tidak melakukan pengobatan secara teratur ada sebanyak $10 \mathrm{KK}$. Dan sisanya yang tidak diketahui ada sebanyak $50 \mathrm{KK}$.

Jumlah KK pada indikator penderita hipertensi melakukan pengobatan secara teratur masih sangat rendah, yaitu hanya $3 \mathrm{KK}$ saja yang sudah memenuhi indikator tersebut. Hal ini dapat dikatakan bahwa masih banyak warga yang terdiagnosis hipertensi namun tidak melakukan pengobatan atau masih banyak warga yang belum mengetahui apakah dirinya terdiagnosis hipertensi atau tidak. Seseorang dapat meninggal secara mendadak karena penyakit hipertensi yang tidak terdiagnosis sejak dini sehingga telah menimbulkan berbagai penyakit komplikasi yang mematikan. Untuk itu hipertensi merupakan prioritas masalah yang harus ditangani dengan serius. Hal ini karena hipertensi disebut juga "silent killer" karena pada sebagian kasus tidak menunjukkan gejala apapun. Perkembangan hipertensi berlangsung secara lambat-laun sehingga sering tidak disadari (Kowalksi, 2010).

Rahmadiana (2012) mengatakan bahwa munculnya masalah kesehatan tidak hanya disebabkan oleh kelalaian individu, namun dapat pula disebakan oleh ketidaktahuan 
masyarakat sebagai akibat dari kurangnya informasi yang benar mengenai suatu penyakit. Park dkk (2015) menyatakan bahwa rendahnya pengetahuan tenaga kesehatan, pasien dan masyarakat tentang hipertensi merupakan penyebab utama tidak terkontrolnya tekana darah, terutama pada pasien hipertensi di Asia.

Nuraeni dkk. (2017) mengatakan bahwa sikap merupakan faktor yang mempengaruhi seseorang dalam melauka suatu tindakan atau perilaku. Salah satu faktor yag mempengaruhi sikap seseorang adalah pendidikan, pengetahuan dan pengalaman. Untuk mendapatka perilau yag baik, maka faktor-faktor yag mempengaruhinya juga harus baik. Untuk meningkatkan perilau pencegahan dan perawatan hipertensi, maka sikap dan faktor lain juga harus ditingkatkan. Salah satu upaya untuk meningkatkannya adalah dengan kegiatan pembelajaran melalui media pembelajaran.

Pemberian informasi dan edukasi melalui media pembelajaran, salah satunya dengan kegiatan penyuluhan kesehatan. Pada dasarnya penyuluhan kesehatan identik dengan pendidikan kesehatan karena keduanya berorientasi terhadap perubahan perilaku yang diharapkan yaitu perilaku sehat. Sehingga mempunyai kemampuan mengenali masalah kesehatan dirinya, keluarga, dan kelompok dalam meningkatkan kesehatannya. Metode yang dapat digunakan dalam memberikan penyuluhan kesehatan yaitu dengan metode ceramah. Metode ceramah adalah suatu cara dalam menerangkan dan menjelaskan suatu ide, pengertian atau pesan secara lisan kepada sekelompok sasaran sehingga memperoleh informasi mengenai kesehatan (Notoatmodjo, 2010).
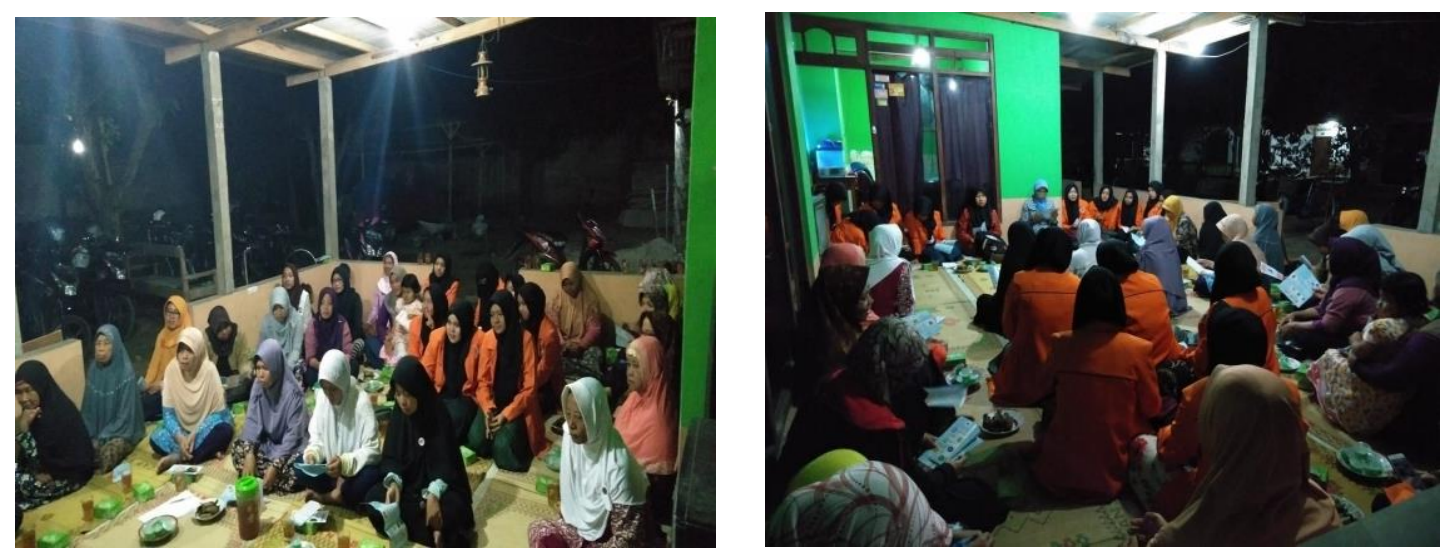

Gambar 1. Kegiatan Penyuluhan

Masalah utama yang terdapat di warga dusun Kretek yaitu hipertensi, maka dilakukan upaya pencegahan dan pengendalian hipertensi dengan cara melakukan penyuluhan menggunakan metode ceramah. Gambaran kegiatan terlihat di Gambar 1. 

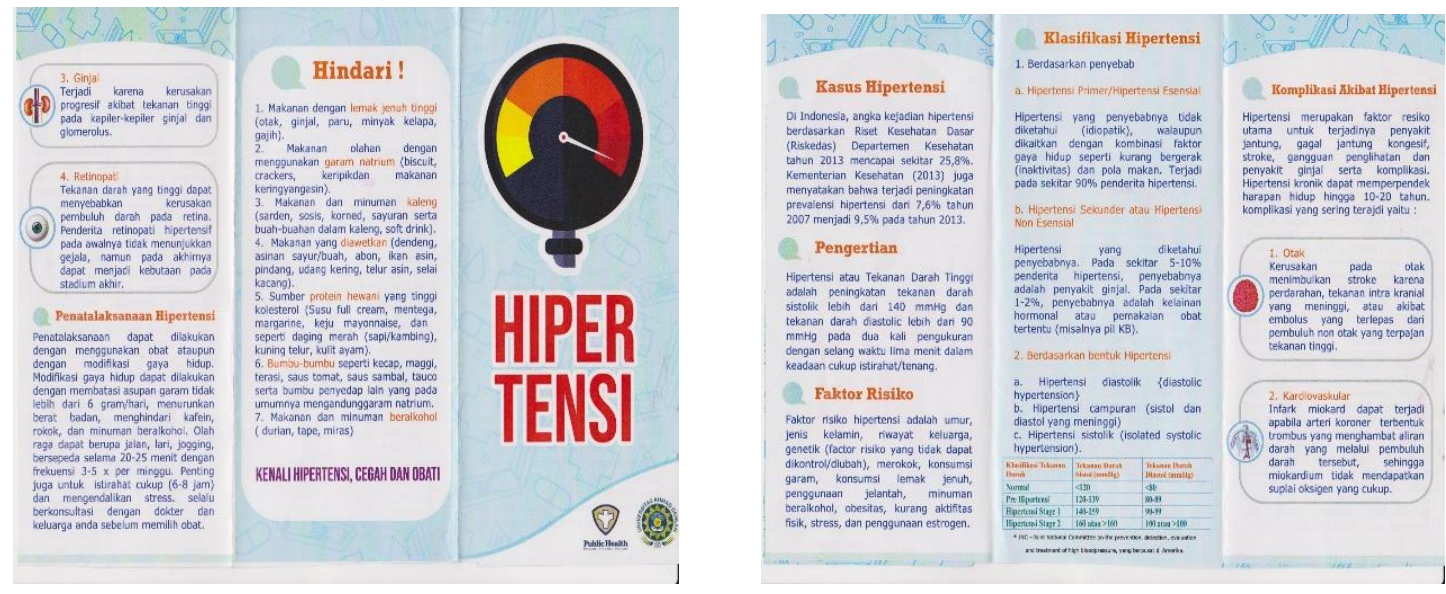

Gambar 2. Media Leaflet tentang Hipertensi

Materi penyuluhan yang disampaikan pada saat intervensi yaitu materi terkait hipertensi diantaranya definisi hipertensi, kasus hipertensi, klasifikasi hipertensi, komplikasi akibat hipertensi, penatalaksanaan dan pencegahan hipertensi. Media yang digunakan pada saat intervensi berlangsung yaitu leaflet. Leaflet yang digunakan tersaji pada Gambar 2. Hal ini dikarenakan leaflet cukup mudah dibuat dan tidak membutuhkan biaya yang besar. Menurut Asfar (2018) yang meneliti tentang pengaruh penyuluhan kesehatan terhadap tingkat pengetahuan dan sikap tentag penyakit HIV/AIDS memperoleh hasil bahwa terdapat peningkatan nilai rata-rata sikap setelah pemberian penyuluhan kesehatan, dikarenakan pemberian penyuluhan dilakukan dengan metode ceramah disertai media leaflet, sehingga segala pesan atau informasi yang disampaikan dapat diterima dengan baik dan jelas oleh pendengar.

Dalam penyuluhan tersebut disampaikan bahwa hipertensi dapat disebabkan karena berbagai macam faktor, diantaranya umur, jenis kelamin, riwayat keluarga, genetik (faktor resiko yang tidak dapat diubah/dikontrol), kebiasaan merokok, konsumsi garam, konsumsi lemak jenuh, penggunaan jelantah, kebiasaan konsumsi minum-minuman beralkohol, obesitas, kurang aktifitas fisik, stres, penggunaan estrogen (Kemenkes, 2014). Berdasarkan faktor risiko tersebut, merokok dapat menjadi salah satu faktor penyebab hipertensi pada responden di RT 09, karena ketika melakukan pengambilan data primer di Dusun Kretek masih terdapat beberapa warga yang merokok. Dalam penelitian Setyanda dkk. (2015) menunjukkan bahwa terdapat hubungan bermakna antara kebiasaan merokok dengan kejadian hipertensi.

Nuraeni dkk. (2017) dalam penelitiannya mengatakan bahwa sebagai salah satu solusi untuk menekan kejadian hipertensi ini dapat dilakukan dengan pendidikan kesehatan 
kepada masyarakat. Hipertensi dapat dikontrol dengan berbagai upaya menjaga gaya hidup. Hal ini dapat tercapai jika pengetahuan masyarakat mengenai pencegahan dan perawatan hipertensi baik. Saat ini kementerian kesehatan berupaya meningkatkan promosi kesehatan melalui komunikasi, informasi dan edukasi. Upaya ini diharapkan dapat meningkatkan pengetahuan, kesadaran dan keinginan masyarakat dalam mencegah dan melakukan perawatan di rumah, sehingga angka hipertensi dapat terkontrol ataupun dicegah pada masyarakat yang berisiko.

Ada beberapa modifikasi gaya hidup yang dapat dilakukan dengan cara membatasi asupan garam tidak lebih dari 6 gram/hari, menurunkan berat badan, menghindari minuman berkafein, rokok, dan minuman beralkohol. Olah raga juga dianjurkan bagi penderita hipertensi dapat berupa jalan, lari, jogging, bersepeda selama 20-25 menit dengan frekuensi 3-5x per minggu. Penting juga untuk cukup istirahat (6-8 jam) dan mengendalikan stress.

Upaya-upaya pencegahan dan pengendalian masih perlu dilakukan. Kegiatan penyuluhan kesehatan sebagai salah satu media pembelajaran seperti ini perlu dilakukan secara rutin agar literasi kesehatan masyarakat dapat meningkat. Dengan adanya penyuluhan kesehatan ini diharapkan dapat digunakan untuk meningkatkan pengetahuan dan kesadaran masyarakat dalam melaukan pencegahan dan penanggulangan hipertensi di rumah.

\section{SIMPULAN}

Pelaksanaan kegiatan pengabdian pada masyarakat telah berjalan dengan lancar. Intervensi dilakukan dengan memberikan penyuluhan kesehatan dengan metode ceramah kepada warga Dusun Kretek terkait prioritas masalah yang ada, yaitu hipertensi. Materi intervensi diberikan dengan penyuluhan secara langsung dan juga dengan pembagian leaflet hipertensi. Intervensi dilakukan sebagai wujud dari penanggulangan masalah hipertensi yang ada di Dusun Kretek. Adanya penyuluhan dan pembagian media promosi kesehatan seperti leaflet berdampak pada peningkatan pengetahuan masyarakat Dusun Kretek.

\section{DAFTAR PUSTAKA}

Asfar, Akbar, Sri A. W. 2018. Pengaruh penyuluhan kesehatan terhadapa tingkat pengetahuan dan sikap tentang penyakit hiv/aids di smp baznas provinsi sulawesi selatan. Journal of Islamic Nursing., 3(1), 26-31. 
Departemen Kesehatan. 2006. Pharmaceutical Care untuk Penyakit Hipertensi. Jakarta : DITJEN Bina Kefarmasian dan Alat Kesehatan Depkes.

Departemen Kesehatan. 2013. Laporan hasil riset kesehatan dasar (riskesdas) indonesia tahun 2013. Jakarta: Balitbangkes Depkes RI.

Dinkes Kabupaten Bantul. 2016. Profil desa jambidan: www.jambidan.bantulkab.go.id, diakses pada tanggal 27 Juli 2018. Yogyakarta.

Kementerian Kesehatan RI. 2014. Infodatin hipertensi. Jakarta Selatan.: Kementerian Kesehatan RI.

Kementerian Kesehatan RI. 2016. Pedoman umum program indonesia dengan pendekatan keluarga. Kementerian kesehatan RI. Jakarta.

Kowalksi, R. 2010. Terapi hipertensi : program 8 minggu menurunkan tekanan darah tinggi dan mengurangi risiko serangan jantung dan stroke secara alami. Bandung : Qanita.

Notoatmodjo S. 2010. Ilmu perilaku kesehatan. Jakarta:PT Rineka Cipta

Nuraeni, A., Mirwanti, R., Anastasia, A., 2017. Upaya pecegahan dan perawatan hipertensi di rumah melalui media pembelajaran bagi masyarakat di kabupaten pagandaran. Jurnal Pengabdian Kepada Masyarakat., 1(3), 174-178

Nuraini, B. 2015. Risk factors of hypertension. J majority., 4(5), 10-19. Fakultas Kedokteran, Universitas Lampung.

Park, J B., Kario., Wang, J G. 2015. Systolic hypertension: an increasing clinical challenge in asia. Hypertension Research., 38(4), 227-236

Rahmadiana, M. 2012. Komunikasi kesehatan: sebuah tinjauan. Jurnal Psikogenis., 1(1), 88-94

Setyanda, Y O G., Sulastri, D., dan Lestari, Y. 2015. Hubungan merokok dengan kejadian hipertensi pada laki-laki usia 35-65 tahun di Kota Padang. Jurnal Kesehatan Andalas., 4(2)

Simamora, Janner P. 2012. Pengaruh karakteristik dan gaya hidup kelompok dewasa madya terhadap kejadian hipertensi di wilayah kerja puskesmas matiti kabupaten humbang hasundutan, Tesis (Tidak Diterbitkan). Medan: Fakultas Kesehatan Masyarakat USU. 
